\title{
The importance of the length of the bilio pancreatic limb (BPL) in any bypass operation: forget the name
}

\section{Editorial}

The long term weight loss outcomes and potential nutritional deficiencies that may arise following bariatric surgery are often overlooked by many practicing bariatric surgeons unless they have a robust long term follow up program. ${ }^{1}$ Bariatric surgery has been plagued by operations that are practiced for few years and then abandoned for long term complications, significant weight recidivism or both (Jejunoileal bypass and vertical banded gastroplasty).

Recently, two new bypass operations (One anastomosis gastric bypass (OAGB), Single Anastomosis Duodeno-ileal bypass with Sleeve gastrectomy (SADI) have emerged that involve re routing the small bowel that are practiced and popularized as the long term solution for super obesity or failure after sleeve gastrectomy. ${ }^{2}$ It can get confusing to some who is just starting to practice bariatric surgery. To answer this question, one must forget about the name of the bypass operation and focus on two variables the length of the BPL, and the common channel (CC). ${ }^{3}$ In addition, one must remember that the small bowel (SB) length is not constant $(5-10.7$ meters $) .{ }^{4}$ It is important to note that because the SB length is variable, if you measure from the ileocecal valve you will get a constant BPL/CC ratio than if you measure from the ligament of Treitz. In addition, recent reports have shown that the length of Roux limb in RYGB is not as important as the BPL and CC length. ${ }^{3}$

What the OAGB and SADI have in common when compared to the standard RYGB is that they have a longer BPL and a larger pouch. So it is natural to assume that they work more by malabsorption than restriction. There is only one RCT comparing OAGB to RYGB showing that OAGB outperforms the RYGB at the expense of significant malabsorptive complications like anemia. This should not come as a surprise, a RCT have shown that in RYGB, a 2meter BPL is superior to a $60 \mathrm{~cm} \mathrm{BPL.}{ }^{5}$

Finally, the goal is long term excellent weight loss without nutritional deficiencies. Hence, achieving superior long term weight loss with significant nutritional problems can hardly be called a success story. Great care, must be practiced when offering bariatric operations with significant malabsorption in the Middle East and Asia, due to lack of long term follow up, low protein consumption in our daily diet and poor compliance with supplemental vitamins. We have to learn from the past, combing significant restriction (small pouch) with significant malabsorption (long BPL) can have disastrous outcomes and should not be practiced. ${ }^{6}$
Volume 3 Issue 4 - 2015

\begin{abstract}
Abdelrahman Nimeri
Bariatric \& Metabolic Institute (BMI), Sheikh Khalifa Medical City, United Arab Emirates

Correspondence: Abdelrahman Nimeri, Chief, Division of General,Thoracic \& Vascular Surgery! Director, Bariatric \& Metabolic Institute (BMI), Sheikh Khalifa Medical City, United Arab Emirates, Tel +97I50208086I, Email nimeri@gmail.com

Received: November 07, 2015 | Published: December 04, 2015
\end{abstract}

\section{Acknowledgements}

None.

\section{Conflict of interest}

The author declares no conflict of interest.

\section{References}

1. Puzziferri N, Roshek TB, Mayo HG, et al. Long-term follow-up after bariatric surgery: a systematic review. JAMA. 2014;312(9):934-942.

2. Sánchez-Pernaute A, Herrera MA, Pérez-Aguirre ME, et al. Single anastomosis duodeno-ileal bypass with sleeve gastrectomy (SADI-S). One to three-year follow-up. Obes Surg. 2010;20(12):1720-1726.

3. Stefanidis D, Kuwada TS, Gersin KS. The importance of the length of the limbs for gastric bypass patients - an evidence-based review. Obes Surg. 2011;21(1):119-124.

4. Landois L, William S. Textbook of Human Physiology. Philadelphia: P Blakiston son \& co; 1889.

5. Nergaard BJ, Leifsson BG, Hedenbro J, et al. Gastric bypass with long alimentary limb or long pancreato-biliary limb-long-term results on weight loss, resolution of co-morbidities and metabolic parameters. Obes Surg. 2014;24(10):1595-1602.

6. Kellum JM, Chikunguwo SM, Maher JW, et al. Long-term results of malabsorptive distal Roux-en-Y gastric bypass in superobese patients. Surg Obes Relat Dis. 2010;7(2):189-193. 